\title{
ASYMPTOTIC EXPANSIONS OF GAMMA AND RELATED FUNCTIONS, BINOMIAL COEFFICIENTS, INEQUALITIES AND MEANS
}

\author{
Neven Elezović
}

Abstract. We give an overview of the use of asymptotic expansions of gamma and related functions - ratio of gamma functions, powers, digamma and polygamma functions. The aim is to introduce a general theory which can unify various particular formulas for factorial functions and binomial coefficients. The connection with inequalities for gamma function is established. Also, a systematic approach to asymptotic expansion of various integral means, bivariate classical and parameter means is given, with applications to comparison of means.

Mathematics subject classification (2010): 41A60, 33B15, 26D15, 26E60, 11B68.

Keywords and phrases: Asymptotic expansion, gamma function, digamma function, factorials, Stirling formula, binomial coefficients, Catalan numbers, means, integral means.

\section{REFERENCES}

[1] J. ABAD, J. SeSma, Two new asymptotic expansions of the ratio of two gamma functions, J. Comput. Appl. Math. 173 (2005), 359-363.

[2] M. Abramowitz and I. A. Stegun (Eds), Handbook of Mathematical Functions with Formulas, Graphs, and Mathematical Tables, National Bureau of Standards, Applied Mathematics Series 55, 9th printing, Washington, 1970.

[3] N. BATIR, Very accurate approximations for the factorial function, J. Math. Inequal., 4, 3 (2010), 335-344.

[4] P. S. Bullen, Handbook of Means and Their Inequalities, Kluwer Academic Publishers, Dordrecht, 2003.

[5] P. S. Bullen, D. S. Mitrinović, P. M. Vasić, Means and theirs inequalities, D. Reidel, Dordrecht, 1988.

[6] J. BukAC, T. Burić And N. Elezović, Stirling's formula revisited via some new and classical inequalities, Math. Inequal. Appl. 14 (2011), 235-245.

[7] T. BURIĆ, N. ElEzović, Bernoulli polynomials and asymptotic expansions of the quotient of gamma functions, J. Comput. Appl. Math., 235, 11 (2011), 3315-3331.

[8] T. Burić, N. Elezović, New asymptotic expansions of the gamma function and improvements of Stirling's type formulas, J. Comput. Anal. Appl., 13, 4 (2011), 785-795.

[9] T. Burić, N. Elezović, New asymptotic expansions of the quotient of gamma functions, Integral Transforms Spec. Funct., 23 (2012), 355-368.

[10] T. BuRIĆ, N. Elezović, Approximations of the Euler-Mascheroni constant and harmonic numbers, Appl. Math. Comput., 222 (2013), 604-611.

[11] T. Burić, N. Elezović, Asymptotic expansions of the binomial coefficients, J. Appl. Math. Comput., 46 (2014), 135-145.

[12] T. Burić, N. ElEzović, Asymptotic expansion of the arithmetic-geometric mean and related inequalities, J. Math. Inequal. 9, 4 (2015), 1181-1190.

[13] T. Burić, N. Elezović, R. ŠImić, Asymptotic expansions of the multiple quotients of gamma functions with applications, Math. Inequal. Appl., 16, 4 (2013), 1159-1170.

[14] T. Burić, N. Elezović, L. VUKŠić, Asymptotic expansions of the gamma function and Wallis function through polygamma functions, Integral Transorms Spec. Funct., 25 (2014), 163-172. 
[15] T. BuRiĆ, N. EleZović, L. VuKŠIĆ, Appell polynomials and asymptotic expansions, Mediterranian J. Math., to appear, DOI 10.1007/s00009-015-0529-z

[16] J. Bustoz, M. E. M. Ismail, On Gamma Function Inequalities Math. Comp. 47 (1986), 659-667.

[17] C.-P. ChEN, N. Elezović, L. VuKŠIĆ, Asymptotic formulae associated with the Wallis power function and digamma function, J. Class. Anal., 2, 2 (2013), 151-166.

[18] C.-P. Chen, N. Elezović, L. Vukšić, Asymptotic expansions of integral mean of polygamma functions, Math. Inequal. Appl., 18, 1 (2015), 255-266.

[19] C. P. Chen, F. QI, The best bounds in Wallis' inequality, Proc. Amer. Math. Soc., 133, 2 (2005), 397-401.

[20] L. Comtet, Advanced combinatorics, Dordrecht, D. Reidel Publishing Company, 1974.

[21] N. ElEzović, Asymptotic expansions of central binomial coefficients and Catalan numbers, J. Integer Sequences., 17, 2 (2014), 1-14.

[22] N. Elezović, Asymptotic inequalities and comparison of classical means, J. Math. Inequal., 9, 1 (2015), 177-196.

[23] N. ELEZović, Estimations of psi function and harmonic numbers, Appl. Math. Comput. 258 (2015), 192-205.

[24] N. Elezović, Generalized Bernoulli polynomials and numbers, revisited, Mediterranean J. Math., to appear, DOI 10.1007/s00009-014-0498-7

[25] N. Elezović, C. Giordano And J. PeČArić, The best bounds in Gautschi's inequality, Math. Inequal. Appl. 3 (2000), 239-252.

[26] N. Elezović, L. Lin, L. VuKŠIĆ, Inequalities and asymptotic expansions of the Wallis sequence and the sum of the Wallis ratio, J. Math. Inequal., 7, 4 (2013), 679-695.

[27] N. Elezović, J. PeČARIĆ, Differential and integral $f$-means and applications to digamma function, Math. Inequal. Appl. 3 (2000), 189-196.

[28] N. Elezović, L. VuKŠIĆ, Asymptotic expansions of integral means and applications to the ratio of gamma functions, Appl. Math. Comput., 235 (2014), 187-200.

[29] N. ElEZOVIĆ, L. VUKŠIĆ, Asymptotic expansions of bivariate classical means and related inequalities J. Math. Inequal., 8, 4 (2014), 707-724.

[30] N. Elezović, L. VuKŠIĆ Asymptotic expansions and comparison of bivariate parameter means, Math. Inequal. Appl., 17, 4 (2014) 1225-1244.

[31] N. ElEzović, L. VUKŠIĆ, Neuman-Sándor mean, asymptotic expansions and related inequalities, J. Math. Inequal, 9, 4 (2015), 1337-1348.

[32] A. ERdÉlyi, Asymptotic expansions, Dover Publications, New York, 1956.

[33] JERRY L. FIELDS, A note on the asymptotic expansion of a ratio of gamma functions, Proc. Edinburgh Math. Soc., 15 (1966), 43-45.

[34] W. GAUTSCHI, Inequalities for gamma and incomplete gamma function, J. Math. Phys. 39 (1959), $77-81$.

[35] H. W. Gould, M. E. Mays, Series expansions of means, J. Math. Anal. Appl. 101 (1984), 611-621.

[36] P. HenRICI Applied and computational complex analysis, Vol. 1, John Willey \& Sons, New York, 1974.

[37] E. A. KaRATSUBA, On the asymptotic representation of the Euler gamma function by Ramanujan, J. Comput. Appl. Math. 135 (2001), 225-240.

[38] D. K. KaZARINOFF, On Wallis' formula, Edinburgh Math. Notes, 40 (1956), 19-21.

[39] D. Kershaw, Some extentions of W. Gautschi's inequalities for the gamma function Math. of Comp. 41 (1983), 607-611.

[40] D. KeRSHAW, Upper and lower bounds for a ratio involving the gamma function, Anal. Appl. (Singap.) 3 (2005), 293-295.

[41] E. B. Leach, M. C. Sholander, Extended mean values II, J. Math. Anal. Appl. 92 (1983) 207-223.

[42] Y. L. Luke, The Special Functions and Their Approximations, Vol. I, Academic Press, New York, 1969.

[43] LusChNY, web page at http://www.luschny.de/math/factorial/.

[44] S. MatTAREI, Asymptotics of partial sums of central binomial coefficients and Catalan numbers, preprint, http://arXiv.math.CO/0906.4290.

[45] E. Neuman, Zs. PÁLes, On comparison of Stolarsky and Gini means, J. Math. Anal. Appl. 278 (2003) 274-284. 
[46] E. Neuman, J. Sandor Inequalities involving Stolarsky and Gini means, Mathematica Pannonica 14/1 (2003) 29-44.

[47] Zs. PÁLES, Inequalities for differences of powers, J. Math. Anal. Appl. 131 (1988) 271-281.

[48] Zs. PÁLES, Inequalities for sums of powers, J. Math. Anal. Appl. 131 (1988) 265-270.

[49] F. QI A new lower bound in the second Kershaw's double inequality, J. Comput. Appl. Math. 214 (2008), 610-616.

[50] F. QI. Bounds for the ratio of two gamma functions, J. Inequal. Appl., Vol. 2010, Article ID 493058, (201), $84 \mathrm{p}$.

[51] S. Ramanujan, The lost notebook and other unpublished papers, Intr. by G. E. Andrews, Narosa Publ. H.-Springer, New Delhi-Berlin, 1988.

[52] F. G. TRICOMI AND A. ERdÉlyi, The asymptotic expansion of a ratio of Gamma functions, Pacific. J. Math., 1 (1951), 133-142.

[53] L. VUKŠIĆ, Seiffert means, asymptotic expansions and related inequalities, Rad HAZU, to appear.

[54] J. WALLIS, Arithmetica Infinitorum, Oxford, England, 1656; Facsimile of relevant pages available in: J. A. Stedall, Catching Proteus: The collaborations of Wallis and Brouncker. I. Squaring the circle, Notes and Records Roy. Soc. London 54 (3) (2000), 293-316.

[55] G. N. WATSON, A note on gamma function, Edinburgh Math. Notes, 42 (1959), 7-9. 